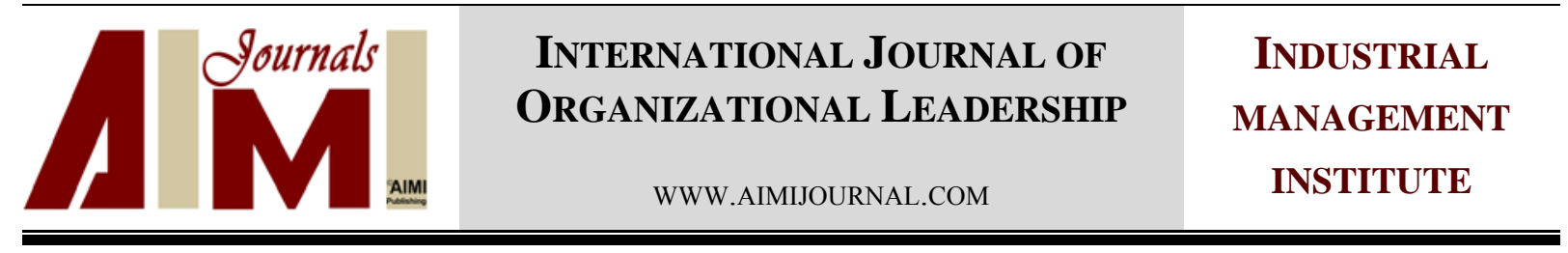

\title{
The relationship between glass ceiling and power distance as a cultural variable by a new method
}

\author{
Naide Jahangirov ${ }^{1}$, Guler Saglam Ari2* ${ }^{2 *}$ Seymur Jahangirov ${ }^{3}$, Nuray Guneri \\ Tosunoglu ${ }^{4}$ \\ ${ }^{1}$ Gazi University, Institute of Educational Sciences, International Trade Education, M.Sc. \\ ${ }^{2}$ Department of International Trade Faculty of Economics and Administrative Sciences, Gazi University, \\ Ankara, Turkey \\ ${ }^{3}$ UNAM-National Nanotechnology Research Center Bilkent University, Ankara, Turkey \\ ${ }^{4}$ Department of International Trade Faculty of Economics and Administrative Sciences, Gazi University, \\ Ankara, Turkey
}

\begin{abstract}
Keywords:

Glass Ceiling, Power Distance

Glass ceiling symbolizes a variety of barriers and obstacles that arise from gender inequality at business life. With this mind, culture influences gender dynamics. The purpose of this research was to examine the relationship between the glass ceiling and the power distance as a cultural variable within organizations. Gender variable is taken as a moderator variable in relationship between the concepts. In addition to conventional correlation analysis, we employed a new method to investigate this relationship in detail. The survey data were obtained from 109 people working at a research center which operated as a part of the nonprofit private university in Ankara, Turkey. The relationship between the variables was revealed by a new method which was developed as an addition to the correlation in survey.

Correspondence: gsaglam@gazi.edu.tr The analysis revealed that the female staff perceived the glass ceiling and the power distance more intensely than the male staff. In addition, the medium level relation was determined between the power distance and the glass ceiling perception among female staff.
\end{abstract}

(C)AIMI Journals

To this day, gender inequality is still an issue and the subject up for debate. Women remain behind men in business and social life and in education opportunities especially in developing countries. Some women cannot work or consent to low wages in business life because they 
choose to take care of their children until a certain age or they do not have enough education or they are preferred less than men for other reasons. Women took more part in business life with economic developments and globalization. Laws on positive discrimination were enacted in some countries. However, the majority of leaders in the world whether in the management level or in bureaucrat seats are men (Meyerson \& Fletcher, 2006).

The glass ceiling concept is a metaphor that emphasizes the inequality between the women and men in business life (Baxter \& Wright, 2000). This concept was first used in a Wall Street Journal article in 1986 to apply the unforeseen obstacles that mid-level women managers confront while proceeding to the top executive levels (Daugherty, 2012). This definition reflected the frustration that women experienced in the working life and used at academic publications since then. This concept refers to women who could enter from the front door of the management pyramid or have talents in this regard, but had to overcome the unforeseen obstacles to do so. The glass ceiling is the unforeseen obstacles women confront while rising in managerial levels (Baxter \& Wright, 2000).

The glass ceiling creates many problems in terms of business performance. First of all, women's enthusiasm and efforts to reach the higher levels could be decreased when they think the opportunities to reach higher levels are limited due to their gender. The obstacles would also decrease the diversity at management levels and constitute an impediment to human resource allocation that organizations require. Even though academic researchers have developed various theories for glass ceiling, studies about the underlying mechanism are still insufficient (Dreher, 2003).

Women were behind men in the economic life in Ottoman Empire. Some kinds of developments were seen in education in the middle of 18th century. Women took active role at social and business life after the establishment of the Republic of Turkey and they earned the right to vote in 1934. With the efforts of education equality, women started to work as teachers, nurses, and civil servants. After 1950's, women's position in the house and business life has changed with the urbanization and industrialization and also women's participation in a non-agricultural sectors has increased. Within that period, women's participation in business was mostly with low skilled jobs (Doğramac1, 1993). Two point four per cent decrease on women's employment rate was realized between 1970-1985 when industrialization accelerated and after that another decline occurred together with the economic crisis in 1994. During this time, women who were only able to find low-wage jobs and work at bad working conditions especially at textile sector and at small factories started having more skilled jobs when they increased their education level. As a result of the increase of their education level as well as the career diversity, significant level of increase was realized on the number of women who had career and worked at the executive level (Aytaç, 1997).

Currently, only 1 per cent of women are top executive managers in Turkey (Aktaş, Algör, \& Cengiz, 2009). According to the Global Gender Gap Report 2014, Turkey is in $125^{\text {th }}$ place with a 0.618 score among 142 countries ( 1 represents the equity). In terms of the sub-indexes realized under the title of the economic participation and opportunities provided to women, Turkey takes the $103^{\text {th }}$ place for being appointed as a member of parliament and executive and takes the $132^{\text {nd }}$ place for labor force participation. In the same report, Turkey takes $102^{\text {nd }}$ 
place in terms of women's participation in professional and technical areas. According to Turkish Statistical Institute's reports, women's employment participation rate throughout Turkey is realized as 25.9 per cent. Following this, Turkey has the lowest women employment participation rate within the European Union members and candidate countries. The percentage of women who are employer and self-employed is 9.9 per cent throughout Turkey. According to 2013 data, 9.3 per cent of women work as executives in the public sector. In 2015 there were only two women ministers in Turkey and the percentage of women ministers at the council of ministers was only 7 per cent.

According to 2008 data and as a result of the survey made within the IMKB100 companies, it is indicated that approximately 0.74 per cent of women take place at the board of directors (Menteş, 2010). In Turkish universities 4 per cent of rectors are women while the ratio of female deans was 11 per cent in 1993 and in 2006 it was 13 per cent. It cannot be taken as a significant improvement in favor of women (Gunluk-Senesen, 2009).

Working women careers are often interrupted by family responsibilities; for this reason, their absenteeism increases and they seek flexible or part-time jobs. This means less working hours and work experience for women (Caceres-Rodriguez, 2011; Sabattini \& Crosby, 2008). According to another survey, employers in Turkey think that women work temporarily and might have children and due to expectations of their families in this direction, they should not be promoted and become top executives (Aytaç, 1997).

Individuals become socialized while learning many values, beliefs, and social relationship in social life they live in and everything in this learning process generates the culture. The regulations examining the interpersonal relationships are the components that create the culture. G. Hofstede and G. J. Hofstede (2005) mentioned five different dimensions that offer an insight into the culture influence on individuals according to the analysis of survey results that was applied to the same leveled IBM employees with same questions at 3 locations in 50 different countries. These five dimensions include individualism versus collectivism, masculinity versus femininity, uncertainty avoidance, long term versus short term orientation, and power distance.

Power distance means the inequality levels in societies and the societies with high power distance level might have effect the level of feeling of the glass ceiling. In Hofstede's (1984) study, Turkey is between $32-33^{\text {th }}$ place as power distance range within 74 countries and the power distance value is 66 . It shows that Turkey's power distance range is substantially high. In the countries with high power distance, it is expected to have high obstacles due to the perceptions of power and usage of power. The surveys revealed that the glass ceiling fact differs in East and West cultures. In this direction, it might become more difficult for women to negotiate those existing obstacles due to high power distance. This study aims to expose the correlation between power distance and glass ceiling. It has importance to reveal this kind of relationship to display the cultural factors which influence the glass ceiling.

While determining the relation between two variables, correlation analysis is used if testing conditions are met. In this study, correlation analysis is thought to be used. However, while correlation analysis gives the level of relation between variables, it does not provide possibility to examine items one by one that constitutes the variables. Therefore, in the study, to see the relation of each factor with the other, a new method that accepts the distance 
between items as a base was developed. By this method, the relations that are the subject of the study are examined deeply.

\section{The Literature Review}

The glass ceiling is an unforeseen obstacle that prevents women from rising to managerial positions and to advance to higher levels of their career despite of their all skills and success in organizations (Jackson, 2001). Women are mostly assigned as mid-level managers in departments with lower strategic importance and are less in charge at higher level (Wirth, 2001).

The reasons which do not let female employees participate in higher executive levels are individual factors, organizational factors, and social factors. Individual factors are women's multiple roles at social life and their own self perceptions. Organizational factors are organization's culture and policies, difficulties to find mentors within organization, and not being able to involve at networks which would create an opportunity for them to progress in their career. Social factors are the assumptions, prejudgments, and assessments against women (Baumgartner \& Schneider, 2010; Boone, Veller, Nikolaeva, Keith, \& Houran, 2013; Karaca, 2007).

Larwood and Wood's (1995) reports based on the interviews with senior female executives shows that they still have a naive belief that having a good education, hard work, and spending enough effort will let them get ahead at higher levels. They believe that men colleagues do not concern about the company's success and are successful to use networks and policy tactics to make advance in their career.

There are some factors that prevent women to be disposed of being in managerial positions in Turkey. Some of these factors are female employees' work overload at home, not receiving support for housework, having main responsibility for kids care, losing their jobs primarily than men during the economic crisis and being more intervened to their appearance (Aktaş, Algör, \& Cengiz, 2009). The results of the study regarding women executives in one of the biggest universities in Turkey indicated that only 8 per cent of women who participated in the research leaned towards women to become top executives (Arbak, Kabasakal, Katrinli, Özmen Timurcanday, \& Zeytinoğlu, 1998). Also, the characteristics of women executives in health sector were examined in another study in Turkey. As a result of this study women prefer to have a less feminine appearance and not to be at the forefront, and they are not feminists. On the other hand, they are married, have a high socio-economic status, have kids, and have strong personality.

In other studies in Turkey, it is revealed that women's maternal responsibilities and family commitments prevent them to become top executives (Ergeneli \& Akçamete, 2004; Örücü, Kılıç, \& Kılıç, 2007). Another underlying reason of women not having a place at top executive levels as male employees is that their social expectations differ from business life (Örücü et al., 2007). Accordingly, the social and cultural conditions can be conceivable as important variables to explain the glass ceiling fact.

Individuals are the members of the society during entire lifetime. But living in a society also means living under social pressure. There are many groups created by individuals in a society. Those groups are confined with culture fact arising from certain rules and traditions 
created to regulate the human affairs. Individuals are required to convene in line with certain rules to create a culture.

Several studies proposed classifications of the cultural dimensions. Hofstede's (1984) classification is a widely used classification in the field of business. The power distance is one of the five cultural classifications which are mentioned in Hofstede studies. According to G. Hofstede \& G. J. Hofstede's (2005) definition, the power distance is connected with the social acceptance of unequal distribution of the power. This establishment can be a school, family, or work place. Thus, the power distance is constructed on less powerful individuals' standard of judgments. For instance, there is a power implemented on the strength of existing power distance applied by teacher on student, parents on child, or supervisor on worker. The way of power distribution is generally explained by more powerful individuals' behavior. It is considered that the power distribution is determined by the behaviors of rulers instead of the behaviors of ruled (Hofstede \& Hofstede, 2005). The societies that minimize the differences resulting from the power signify the low power distance culture and societies that institutionalize the power and signify the high power distance culture (Terzi, 2004).

The distance that power created among the peoples of the society occurs according to the scale of the values and norms of the society and differences in power. It is known that growing in different countries until a certain age, being descended from certain families, and studying at principal education institutions add distinctions to the individuals regardless of that individual's other capabilities or efforts (Varoğlu, Basım, \& Erçil, 2000). Therefore, men become exclusive in the society because of having power. On the other hand, it is considered that women and men are different in perceiving power distance and men's perception of power distance is higher than women's (Terzi, 2004). According to Sargut (1994) less powerful people in countries with high power distance acknowledge that power does not redound on individuals equally. Rosener (1990) mentioned that female employees attribute their power to their charismas, communication ability, diligence, or personal qualifications such as personal relationships instead of their organizational position.

Considering the differences between societies with low and high power distance, the human inequality at countries with high power distance is something that expected and desired. The statute is compensated by restrictions and obedience and dependence form a basis and individuals with or without education have same authoritarian value (Hofstede \& Hofstede, 2005). These determinations make us think that the glass ceiling fact which emphasizes the inequality within the women and men is an important and common situation at societies with high power distance.

Consequently, the level of power that individuals of society perceive is actually relevant to that society's cultural and the family structure. Boys in Turkey and many other countries in the world grow up more freely and more supported as compared to girls. It appears that in the societies with high power distance the representative of the power is seen as man; therefore, this distance generally is being constituted by male individuals and this distance is being perceived more by women who do not represent the power. Collective mental programming of the human mind that G. Hofstede and G. J. Hofstede (2005) mentioned will develop this way on individuals who has been raised up this way due to their family roots and social structure. After a while perception in the mental programming will be in direction that 
inequality is normal and women will live by accepting this in equality. The acceptance level of the inequality will be as high as the power distance.

Especially in rural regions in the countries like Turkey, girls who were exposed to discrimination in their childhood would frequently have lack of self- confidence and feel left behind when they grew up. Following this, these children might consider inequality as normal because they were exposed to discrimination while their growth. Especially in societies with high power distance, this inequality would be perceived intensively by individuals who feel powerless. When individuals who have been acknowledged the current inequality get a start in business, they would meet obstacles due to their genders and would not spend time to remove these obstacles. Female employees who want to fight against the obstacles will be obliged to make great effort. Considering the relationship between the level of power distance at society and the obstacles female employees meet, it is discussed that actually some obstacles are occurred due to the current inequality and at the same time, the current power distance effect female employees to have difficulty in overcoming the obstacles. In this direction the following hypothesizes are developed:

$\mathbf{H}_{1}$ : Individuals perception of power distance varies by gender.

$\mathbf{H}_{2}$ : Individuals perception of glass ceiling varies by gender.

$\mathbf{H}_{3}$ : The relationship between power distance perception and glass ceiling perception differ between men and women.

\section{Method}

The questionnaire consisted of the demographic variables and questions and it was used to measure the power distance and the glass ceiling perceptions. There were 7 questions to determine participants' demographic variables. The 10 questions regarding power distance which generated the survey are the ones Varoğlu et al. (2000) used in their studies regarding the power distance. These questions were translated to Turkish and were enhanced. Their validity and reliability was conducted using the measurement tools that appear in Hofstede's (1984) survey and the questionnaire related to the predicate on the cultural point of views was developed by Maznevski, DiStefano , and Nason (1993). The 27 questions out of 32 which were prepared to measure the glass ceiling perception were taken from Akçamete's (2004) study. The other 5 were obtained from Zeybek's (2010) study. All questions were measured by likert-type scale scoring from 1 (strongly disagree) to 5 (strongly agree).

Scale's reliability was measured using the criterion's mathematical formula and in MATLAB programming language. The reliability scale of the power distance questions was contrived as $\alpha=0.614$ and the relativity scale of the glass ceiling questions is contrived as $\alpha$ $=0.903$. The survey was conducted in a research center of a university in Ankara and the research center's work field was nanotechnology. Academic staff, research assistants, engineers, administrative and technical personnel constituted the personnel of this center. The analyzable questionnaire number was 109 out of 111 questionnaires delivered to the working group of the survey.

First of all, demographic data was analyzed and the frequency distributions and percentages of the staff answers to the demographic questions are indicated in Table 1. Thirty nine point four per cent of the staff who answered the survey was women and 60.6 per cent of 
them were men. Considering the attendees' marital status, 65.1 per cent of respondents were single and 34.9 per cent of them were married. In terms of the education level it was seen that 31.1 per cent of the respondents were graduated and 51.4 per cent of them were $\mathrm{PhD}$ students. Respondents' positions showed that 9.2 per cent of them were administrative and technical personnel, 10.1 per cent of them were engineers, 28.4 per cent of them were research assistants who were getting a master's degree, 42.2 per cent of them were research assistants who were getting doctoral degree, and 10.1 per cent of them were the academicians.

Table 1

Demographic Profile of the Sample

\begin{tabular}{|c|c|c|c|}
\hline \multicolumn{2}{|l|}{ Demographic variables } & \multirow{2}{*}{$\begin{array}{c}\text { Frequency } \\
43\end{array}$} & \multirow{2}{*}{$\begin{array}{c}\text { Percentage (\%) } \\
39.4\end{array}$} \\
\hline Gender & Female & & \\
\hline & Male & 66 & 60.6 \\
\hline \multirow{5}{*}{ Age } & $18-25$ & 46 & 42.2 \\
\hline & $26-30$ & 39 & 35.8 \\
\hline & $31-35$ & 12 & 11.0 \\
\hline & $36-40$ & 7 & 6.4 \\
\hline & 41 and above & 5 & 4.6 \\
\hline \multirow[t]{2}{*}{ Marital Status } & Married & 38 & 34.9 \\
\hline & Single & 71 & 65.1 \\
\hline \multirow{4}{*}{ Number of Children } & None & 84 & 77.1 \\
\hline & 1 & 10 & 9.2 \\
\hline & 2 & 13 & 11.9 \\
\hline & 3 and more & 2 & 1.8 \\
\hline \multirow[t]{6}{*}{ Education } & Elementary & 3 & 2.8 \\
\hline & Highschool & 4 & 3.7 \\
\hline & Associate Degree & 1 & 0.9 \\
\hline & Bachelour & 11 & 10.1 \\
\hline & Masters & 34 & 31.1 \\
\hline & Doctorate & 56 & 51.4 \\
\hline \multirow[t]{4}{*}{ Position } & $\begin{array}{l}\text { Administrative Staff } \\
\text { Engineer }\end{array}$ & $\begin{array}{l}10 \\
11\end{array}$ & $\begin{array}{c}9.2 \\
10.1\end{array}$ \\
\hline & Researcher (MS) & 31 & 28.4 \\
\hline & Researcher $(\mathrm{PhD})$ & 46 & 42.2 \\
\hline & Associate Professor & 11 & 10.1 \\
\hline \multirow[t]{6}{*}{ Working Experience } & Less than 1 year & 24 & 22.0 \\
\hline & $1-5$ years & 57 & 52.3 \\
\hline & $6-10$ years & 16 & 14.7 \\
\hline & $11-15$ years & 6 & 5.5 \\
\hline & $16-20$ years & 1 & 0.9 \\
\hline & 21 years and more & 5 & 4.6 \\
\hline
\end{tabular}

\section{Results}

The answers' frequency and percentage distribution of female and male staff were assessed. The observations provided compelling evidence that female and male staff answered the questions in the same direction (agree or disagree). To clarify the trends, Likert's 5 points scale was changed to trends scale and Likert's 5 points scale answers of 1, 2, 3, 4 and 5 was replaced respectively with $-2,-1,0,1$ and 2 answers in trends scale. While the positive numbers at trend scale represented the agreement trend, the negative numbers represented the disagreement trend. Neither agree nor disagree answer represented the value of zero because 
it meant that there was no trend. All control questions were calculated reversely for the estimations using the trend scale. In order to calculate these questions reversely, the results of the survey answers were converted to the trend scale and then were multiplied by minus. The 5th question from the power distance questions was the control question because all answers in direction of agreement to all other questions had the meaning for high power distance; the disagreement to 5 th question represented this meaning.

Figure 1 summarizes the female and male staff's displayed average trend as a result of their answers to the power distance questions. The arithmetic mean method was used to find out the trend. The most important finding at Figure 1 is that male staff demonstrated more agreement trend than female staff to every question except 4th question. The difference between the female and male staff's displayed trends as results of their answers to the power distance questions can be seen at Figure 2.

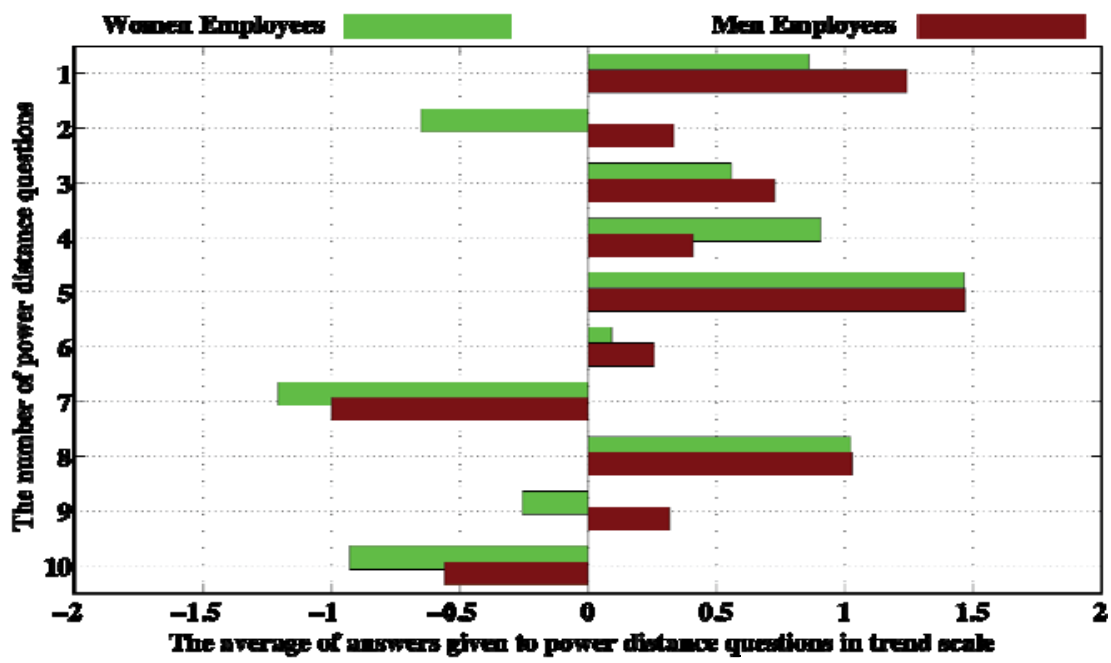

Figure 1. The female and male staff's displayed trend as results of their answers to power distance questions

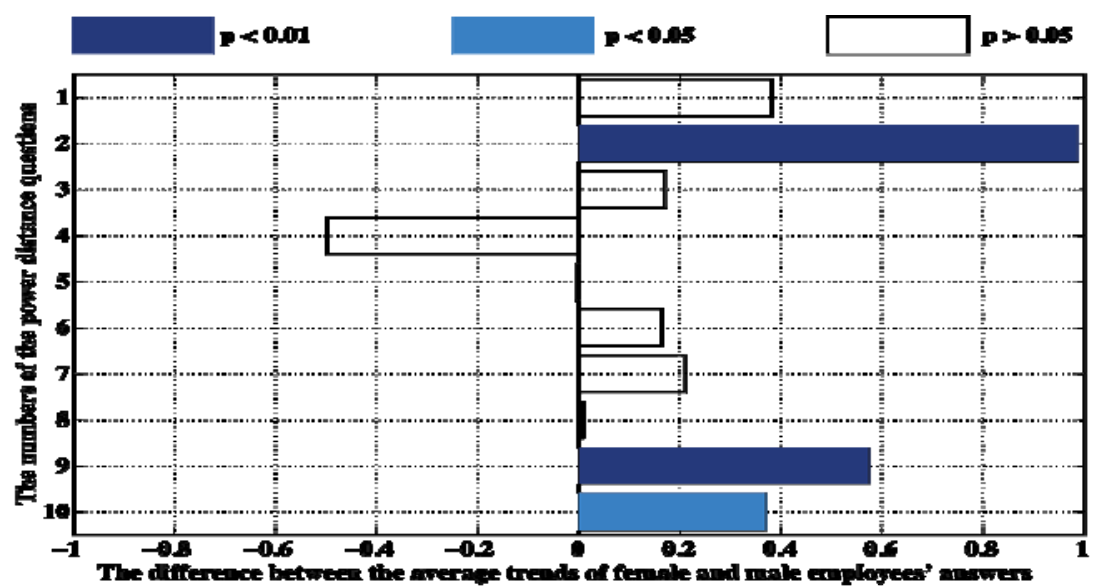

Figure 2. The difference between the female and male staff's displayed trends as results of their answers to the power distance questions

The specified differences of Figure 2 were examined with the independent samples t-test using SPSS to find out if they were significant. The significant differences are shown with dark blue $(\mathrm{p}<0.01)$ and light blue $(\mathrm{p}<0.05)$ and the checkboxes related to the non- 
significant differences were left blank. Questions 2 and 9 are the questions that men demonstrated agreement and women demonstrated disagreement trend and at the same time they were the questions with the highest trend differences. It was presented that men demonstrated more agreement to the power distance questions than women and women demonstrated more agreement to the 4 th question. The difference value of this question was high but non-significant; the reason for this might be respondents who perceived this question with different senses. As it is mentioned on the conceptual framework, staff expects to be told about the actions needed in cultures with high power distance (Hofstede \& Hofstede, 2005). With this aspect while 4th question measured the power distance, it did not have a meaning of being on power's side; in this regard, it was considered from a different angle. After the evaluation of questions, for testing the first hypothesis independent sample t-test was used and as a result of the test, the first hypothesis was supported (female mean $=3.18$, male mean $=3.42, \mathrm{p}<0.05)$. Accordingly, power distance differed by gender.

\section{Analysis of the Glass Ceiling Questions}

The trends obtained from data are shown in Figure 3. It is seen that female and male staff generally answered in the same direction as in the previous survey. Contrary to the findings, female and male staff answered questions 5, 10, 11, 13, 17, 25, 27, 29, and 30 in opposite direction. Both genders gave clear but dissimilar answers to questions 10, 11, and 27. These questions were respectively the equal opportunities for training which were given to women and men in business world; women executives had better communication with their superiors and subordinates than men executives in business world and women were exposed to discrimination on salary, subsidy, and statue issues.

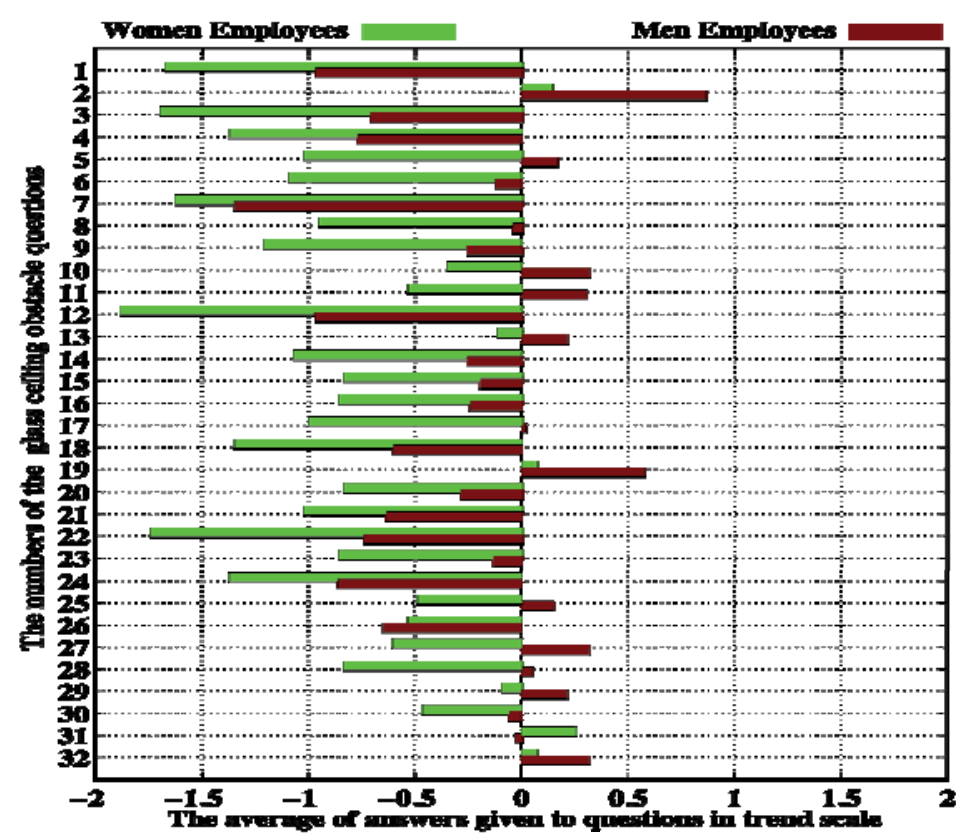

Figure 3. Female and male staff's average trends of answers given to glass ceiling questions

As it is seen in Figure 3, the questions that female staff's presented their opinion of disagreement in no uncertain terms were questions $1,3,7$, and 12. These questions were 
respectively women are not suitable for the environment of business life, women's abilities are limited to become top executives, primarily women should be misemployed when there is need for lay-off (during crisis period), and women should not be appointed as top executive levels. As it is shown, all these questions transparently had a meaning of loss for women. This impression also explained why male staff gave more clear answers than female staff to question 19 that top executive women perform higher performance than top executive men; because this question had a meaning of loss for men.

The differences between trends of female and male staff's answers given to glass ceiling questions are represented in Figure 4. Comparing this figure with power distance difference figure (Figure 2) it is seen that male staff trend differences were bigger than female staff in glass ceiling figures. Independent sample t-test was used for testing the second hypothesis and as a result of the analysis, the second hypothesis was supported (female mean $=2.89$, male mean 2.95, $\mathrm{p}<0.05$ ).

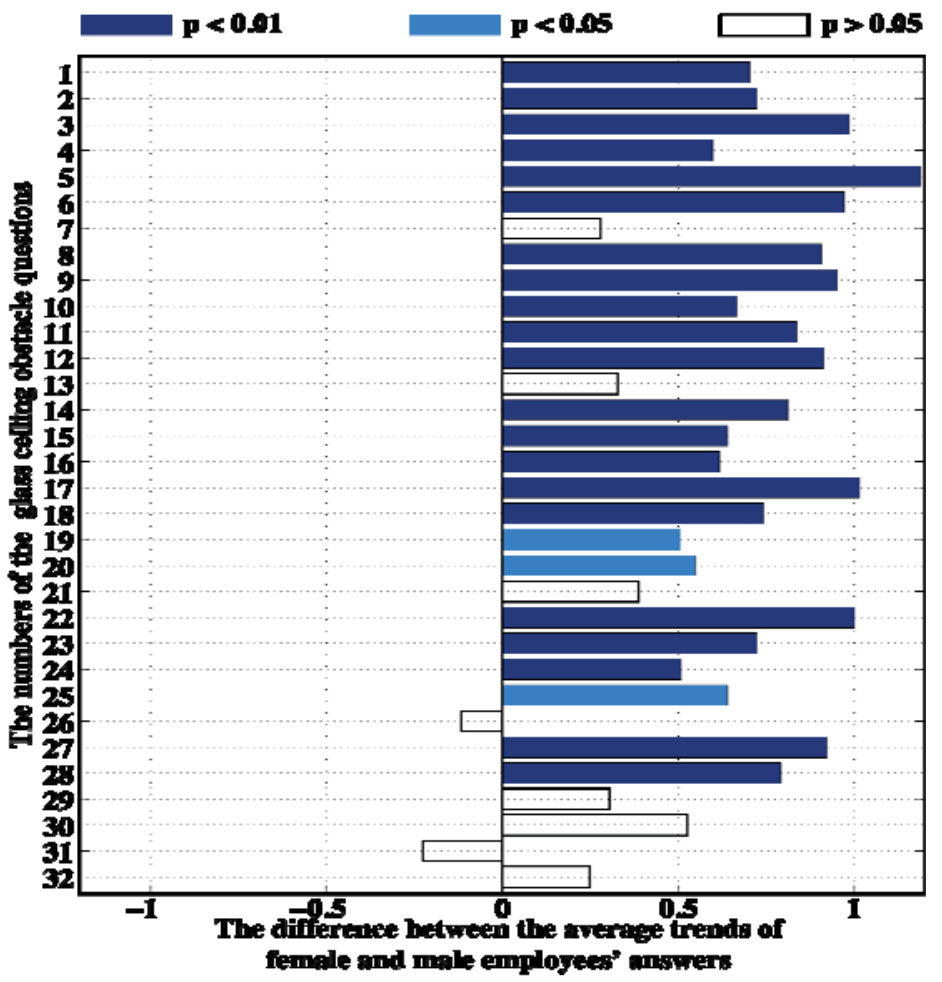

Figure 4. The differences between female and male staff's displayed trends of answers given to glass ceiling questions

\section{The Analysis of the Relation between Power Distance and Glass Ceiling}

Total correlations between the answers given to power distance and glass ceiling questions are given in Table 2. The control questions are calculated reversely while the analysis of this section is executed as it was mentioned in the previous section. It was seen that the obtained value is not significant for female staff $(p>0.05)$. The reason can be that some questions were not propounding the perception differences between the female and male staff. 
Table 2

The Values of the Calculated Correlations between the Answers Given to Power Distance and Glass Ceiling Questions

\begin{tabular}{lll}
\hline & Female & Male \\
\hline All questions & 0.28 & $0.41^{*}$ \\
\hline The questions that differences were significant & $0.56^{*}$ & $0.35^{*}$ \\
\hline$* \mathrm{p}<0.01$ & &
\end{tabular}

In this situation it is thought that the correlation analysis can be done without taking into account these kinds of questions. As is seen in Figure 2, only the glass ceiling questions numbered 2, 9, and 10 exposed significant differences between the female and male staff's perceptions. As is presented in Figure 4, the power distance questions including 1, 2, 3, 4, 5, $6,8,9,10,11,12,14,15,16,17,18,19,20,22,23,24,25,27$, and 28 exposed the significant difference. The correlations for these questions are determined respectively as 0.56 and 0.35 (Table 2).

As a result of the analysis it is seen that the third hypothesis was supported $(p<0.01)$. The relation between power distance and glass ceiling was higher in female than male staff as it was mentioned in theoretical section. In the correlation analysis it can be seen from the degree of relation between variables that it does not provide possibility to examine items one by one that constitutes the variables. Therefore, in the current study, to see the relation of each factor with the other, a new method that accepts the distance between items as a base was developed. By this method, the relations that were the subject of the study were examined deeply.

The chosen questions did not have conceptual integrity as in factor analysis but had common point in the questions stating that female and male staff had different reactions. As a result, the correlation analysis differs according to the chosen questions. In this case, it is seen that the clear judgment cannot be attained by making the correlation analysis. The more developed method has to be used to fill the deficiency. Obtained data is approached with such method in next section.

\section{The Assessment of the Answers Given to Power Distance and Glass Ceiling Questions by a New Method}

As it is mentioned on the section that the correlation analysis have been done, the clear judgment cannot be reached on the basis of the correlation between the answers given by female and male staff to power distance and glass ceiling questions. The main cause of this is that some questions have functionality to reveal the diversity of female and male staff's views and some questions do not have such functionality. The estimation based on the questions with such functionality, the female staff's power distance and glass ceiling perception is found to be more correlated than male staff and the exact opposite results are concluded when the other questions are included in the estimation. There is a need for the analysis method which reveals every question's relations with every question of the questionnaires in detail and apprehensible to solve this problem.

It is possible to measure the proximity between any two questions of the survey based on the answers of survey respondents. The distance between two questions' concept which we 
identified for this is as such, for example the distance between $\mathrm{n}$ and m numbered questions based on female staff's answers can be found by following equation mentioned below:

$$
d_{m m}=\sqrt{\sum_{i=1}^{t=N_{R} \frac{\left(m_{i}-m_{i}\right)^{2}}{N_{R}}}}
$$

In this equation, $\mathrm{d}_{\mathrm{nm}}$ represents the distance between questions $\mathrm{n}$ and $\mathrm{m}, \mathrm{n}_{\mathrm{i}}$ and $\mathrm{m}_{\mathrm{i}}$ represent the value of the i'th female staff's answers to questions numbered $\mathrm{n}$ and $\mathrm{m}$ according to the trend scale, and $\mathrm{N}_{\mathrm{k}}<$ represents the number of the total female staff that participated in the survey. Any question's distance to per question can be found by the answers of female and male staff using this formula. Besides some questions' reverse meaning might be close to the other question, therefore, each 42 question's answers at trend scale are duplicated by minus and counted. In other words, distance between 84 questions is calculated on condition that the half of them should be the reverse of the other half. The below mentioned method is used to make obtained data interpretable.

The power distance and glass ceiling questions charts can be prepared by depending on female and male staff's answers to these concepts. Hence, the question distance data that we acquired below should be adapted into such chart. If this survey comprised of only two questions, it would be enough to place two points representing two questions in two dimensional places at the distance found by the formula. But there are 84 points in question; therefore, it is only possible to place the points according to the distances situated with 84 dimensional spaces. The real distance between some of the questions should be shortened and some of them should be extended to demonstrate the above obtained data in two dimensional plot. While doing this, the physical optimization technique has been used to obtain the plot which shows the least deviation from the real distances.

Primarily, each point which represents both questions in two dimensional spaces with a random position is determined. Afterwards, it is assumed that there is an elastic bow between two points. Each bow's free length is equalized to the real length between two points of the bow. Thereby, if the points representing the questions are in a more distant point than the real length, they would intend to convert and would intend to diverge if they are in closer distance. It is assumed that the fractional force which is directly proportional but aback with their speed is applied to each point to have this system and reach certain balance point. With the help of the friction, the points at the system converge towards the optimum value with the least deviation from the real length between themselves. This optimization is executed numerically in MATLAB programming language based on the below physical formula. The force that has an effect on the question numbered $n$ can be written out as follows:

$$
\vec{F}_{n}=-b \vec{v}_{n}+\sum_{n=m=1}^{m=N_{s}} k\left(\vec{r}_{m}-\vec{r}_{n}\right)\left(1-\frac{d_{n m}}{\left|\vec{r}_{m}-\vec{r}_{n}\right|}\right)
$$

Here $\vec{F}_{n}$ represents the force which has an effect on the point representing the question numbered $\mathrm{n}$. The friction effect which generates this power and the effect arising from the point being tied to other points with string compose the first and second terms at the right side of the formula. Hereby, the constant of friction number $b$ is set to 0.01 and constant of spring number $\mathrm{k}$ is set to 1 . It was determined that making changes on these numbers do not have any impact on the results. The Euler method was used in order to have the optimization 
done numerically. The optimization was suspended when the total forces on the points representing the questions and the speeds vanished and the results generated are shown in Figure 5 and Figure 6.

The plots obtained as a result of the optimization done according to the distances between the points representing the questions are entitled as optimum distance plots. The horizontal and vertical axes do not have any meaning; therefore, they were not marked up. The diagrams can be revolved totally because only the points' distances to each other have an importance. It is possible to find many specialties which were mentioned in previous sections together in these figures.

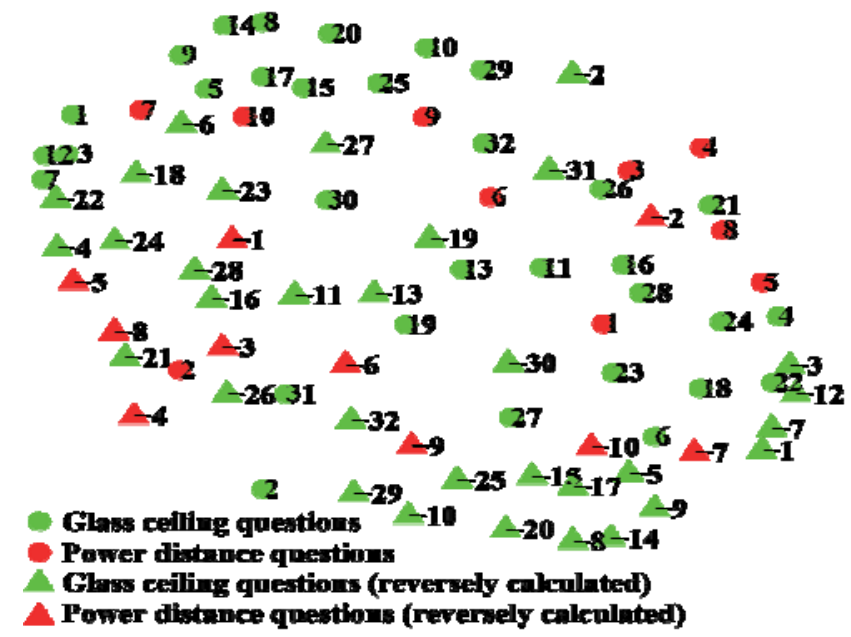

Figure 5.The optimum distance diagram obtained based on female staff given answers

The points close to each other in Figure 5 and Figure 6 demonstrate the questions with similar meanings. For example, there is proximity between the question number 3 of the glass ceiling (women's abilities to become top executives are limited) and the question number 12 (women should not be appointed as top executives) and this proximity is seen in both women and men's optimum distance diagrams.

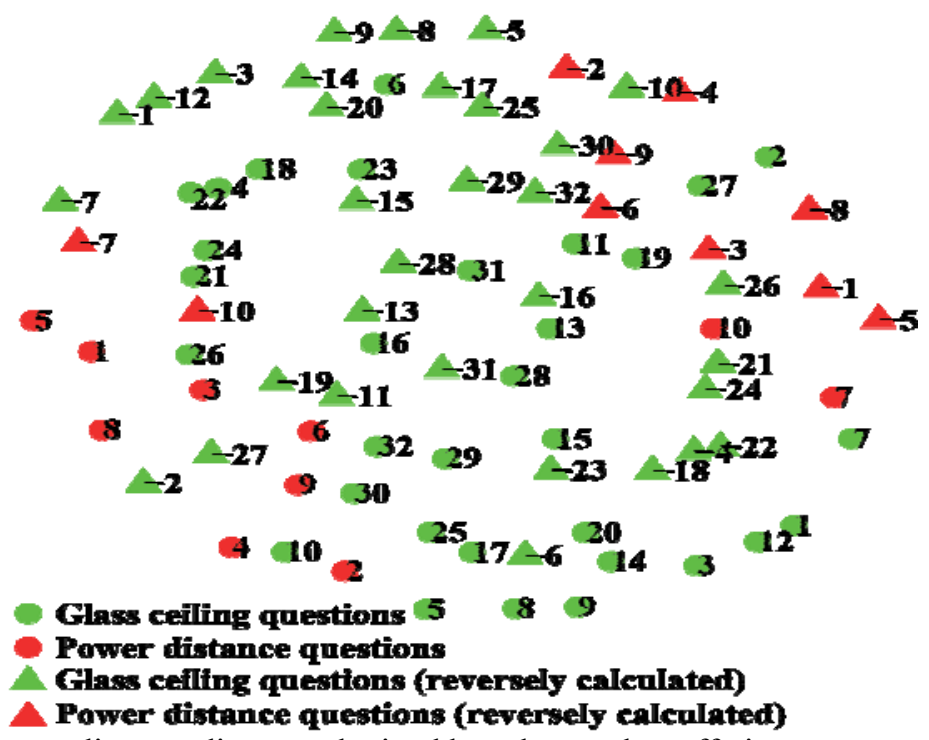

Figure 6. The optimum distance diagram obtained based on male staff given answers 
As a result of optimization, each question's reverse is found in the question's reflection according to the figures centre point. In other words if an arrow is drawn from the figures centre points to any question, the arrow's 180 degree rotated state would be oriented towards the reverse of the question. If the answers given to questions indicate the clear trend, it increases the distance between the question and the reverse of the question. Therefore, the answers of the questions with clear trend are located at the outer side which is far away from the centre of the optimum distance diagrams. If the answers do not indicate the clear trend, the points representing these questions appear at the centre of the figure. For example, while the question numbered 7 of the glass ceiling questions (primarily women should be misemployed when there is need for lay-off during crisis period) gets the clear reaction from both female and male staff; the question numbered 13 (female executives support their staff's career development more than male executives) received the answer with neutral trend from both female and male staff. Concordantly, the point representing the question numbered 13 of the glass ceiling obstacle (female executives support their staff's career development more than male executives) is located close to the centre in both female and male staff's optimum distance diagrams; the question numbered 7 of the same section (primarily women should be misemployed when there is need for lay-off during crisis period) is seen away from the centre in both two figures. In parallel with section 4.3, the point representing the question numbered 19 (top executive women perform higher performance than top executive men) is seen close to the centre in female staff's diagram meaning that there is no clear trend; same question is seen far from the centre in male staff's diagram.

The most important feature of Figure 5 and Figure 6 is to execute visually how the power distances and the glass ceiling obstacle concepts are shaped according to female and male staff's perceptions. When examining these variable's distribution as a whole in male staff's optimum distance diagram (Figure 6), it is determined that the points representing power distance questions are closer to each other and placed far from the points representing glass ceiling obstacle questions. The points representing power distance questions are more disorderly and nested with the points representing glass ceiling obstacle questions in diagram based on female staff's answers (Figure 5). The quantitative conclusion is that female staff's perceptions of power distance and glass ceiling obstacle are more related than male staff. In order to make the results as a quantitative, a scale which determines the relations of variables with each other in the optimum distance diagram as a whole is developed. The important thing in these diagrams is the distance between the points, so the scale is constituted on the relation between these distances. Primarily, each question's average distances between all other questions are found out to calculate the scale. The selected question's distances to all other questions are added and then divided to the number of all other questions to get this value. The smallest and the biggest values on the row which consists each question's average distances to other questions are registered as $\mathrm{R}_{\min }$ and $\mathrm{R}_{\max }$. Afterwards, the distance between each questions measuring one of the concept and the other questions measuring the other concept are added and then divided to multiplier of the question numbers which consists the both concepts to find the average distance between power distance and glass ceiling. The obtained value is registered as $\mathrm{R}_{\text {ort }}$. The distances used in this calculation are the distances in 
optimum distance diagram. The relation scale between two concepts by using the registered values in the optimum distance diagram is identified according to the formula shown below.

$$
\eta=\frac{R_{\max }-R_{o r t}}{R_{\max }-R_{\min }}
$$

The relation scale calculated according to this formula $\eta$ takes values between 0 and 1 . The relation scale having big values signifies that there are more close relation between the two concepts. As a result of the calculations based on diagrams shown in Figure 5 and Figure 6 , the relation scale between women and male staff's perceptions of power distance and glass ceiling obstacle concepts is found as below.

The relation between female staff's power distance and glass ceiling obstacle perception: $\eta=0.520$. The relation between male staff's power distance and glass ceiling obstacle perception: $\eta=0.400$. While this result supports hypothesis three in a different method, it also reveals that the relation between female staff's power distance and glass ceiling perceptions is more than male.

\section{Discussion and Conclusion}

The present study examined the relationship between glass ceiling, power distance, and gender. Additionally, a new method was developed which was an alternative to the correlation analysis. At the end of the research, it is proposed that male staff displayed more agreement trend than female staff to every question except one question of power distance questions. It is concluded that women displayed more agreement trend to 4th question. This question stated that well managed organization comprises the structure and mode of communication that fullest extent of things to do are well indicated to subordinates and do not leaves even any unclear small area. Staff expects to be told what to do in the cultures with high power distance (Hofstede \& Hofstede, 2005). The reason women answered this question with more agreement trend than men is that women might have thought that having all rules written down with every details might solve the discrimination and bring the equal opportunities to men and women in business world which they think men is dominated.

It is observed that male and female staff's answers to the questions measuring the glass ceiling perception (the equal training opportunities are given to women and men at business world, female executives have better communication with their superiors and subordinates than male executives, and women are exposed to discrimination on salary, subsidy and statue issues) were clear but in different direction. Considering the answers' trend to the glass ceiling questions, it is observed that female staff generally have clearer trend than male staff. This situation presents that glass ceiling obstacle is reality and this obstacle is perceived substantially by women.

One of the reasons of female staff who gave more clear reaction to the glass ceiling obstacle is identified as the effect of "avoiding the lost" which Tversky and Kahneman (1991) revealed as a result of their studies and this effect explains that while individuals make choices, their subjective value to the losses is more than the loss's objective value. The glass ceiling questions are generally questions about whether women are sufficient for business life 
and this type of questions expresses the loss meaning for female staff; therefore, female staff evaluated these questions clearly in direction of disagreement.

The questions that female employees represented clearly in the direction of disagreement are "women are not suitable for the environment of business life", "women's abilities are limited to become top executives", "primarily women should be misemployed when there is need for lay-off (during crisis period)", and "women should not be appointed to top executive levels". These questions transparently comprise the meaning of a loss for women. In consideration of all questions, the correlations between the answers given to power distance and glass ceiling by female and male staff are respectively found as 0.28 and 0.41 . The value found for female staff is seen as a meaningless value $(p>0.05)$. Therefore, it is not possible to make comparison between the two numbers. The reason of finding the significant correlation value for male staff while not being able to find such a value for women is because of some questions which do not provide the ground to execute the perception differences between female and male staff in this analysis. In this case the correlation analysis is required to be executed by excluding this kind of questions.

The significant variance with 0.29 unit $(\mathrm{p}<0.01)$ comes up in the trend scale when the female staff displayed average trend is exiled from the male staff's answers given to power distance questions. This situation supports the first hypothesis one and according to this result it is seen that male staff are on the side of the power. The significant variance with 0.71 unit $(\mathrm{p}<0.01)$ comes up in the trend scale when the female staff displayed average trend is exiled from the male staff displayed average trend of the answers given to glass ceiling questions. This situation supports the second hypothesis. In the analysis that was executed with taking into consideration the questions which reveals the differences between the female and male staff's perceptions, the correlations between the answers of power distance and glass ceiling questions of female and male staff are respectively found as 0.56 and 0.35 . This situation demonstrated that there was a significant relation between the female and male staff's power distance and glass ceiling perceptions and varied by gender and third hypothesis is supported. These results supported the opinion of the relation between power distance and glass ceiling concepts that occurs more in female staff than male staff as it was mentioned in theory section. The method used hereby bears a resemblance with factor analysis. Although the chosen questions do not have the cognitive integrity as in the factor analysis, but they have the common point due to the questions which women and male staff gave different responses. Consequently, it is observed that the correlation analysis differs according to the chosen questions. Following this, it is perceived that it is not possible to reach the clear judgment by doing the correlation analysis. A different method is developed to eliminate this problem and the new method is applied to ensure two different correlation results. Each questions distance to other question is found according to the answers given by female and male staff. Besides, some questions reverse meaning could be close to another question; therefore, each 42 questions' answers of this questionnaire in the trend scale is counted on by multiplying with minus. In other words, the distance between 84 questions on condition that the half of them is the opposite of the other half is calculated. This diagrams which are found according to the optimization result done by the distance between the points representing the questions are named as optimum distance diagrams. In these diagrams shaping of power distance and glass 
ceiling according to the women and male staff's perception is visually revealed. It is observed that the points representing the power distance questions are closer to each other and it is far from the points representing the glass ceiling in male staff. The points representing the power distance questions are more disorderly and more nested with the points representing the glass ceiling questions in female staff. Hence, it is concluded that the relation between power distance and glass ceiling perception in female staff is more than male staff. The relation scale between the questions $(\eta)$, takes a value between 0 and 1 . The relation scale's taking big values signifies closer relation between the two concepts. As a result of the calculations, the third hypothesis are supported as it can be seen in the relation scale which displays the relation between the female and male staff perceptions of power distance and glass ceiling and it is executed that the relation of female staff's perceptions between power distance and glass ceiling is more than male staff.

As a result of the study, it is possible to mention the existence of glass ceiling in the sense of women and there is a direct proportion between the women's perceptions of power distance and glass ceiling. Also at the end of the research it is concluded that the most of the participants had masters and $\mathrm{PhD}$ degree, so although the research center had the qualified and skilled staff, power distance and glass ceiling perception difference between female and male staff was not disappeared.

Female staff's glass ceiling perception is related to the acceptation of the existing discrimination and glass ceiling perception increases when the power distance increases. When the glass ceiling perception increases, the acceptance level of discrimination which is identified for power distance also expands. Besler and Oruç (2010), Bingöl (2006), and Yoğun Erçen (2008) argued that certain strategies can be applied by organizations or women to eliminate the glass ceiling or get out of the current situation. These strategies refers to concepts such as female staff having the university education or vocational training, improving their social relations, attending the career development programs and performing the high performances, getting help from the mentor, and applying the positive discrimination. These strategies except the positive discrimination are the strategies that organizations should support and women should claim responsibility for most of them. Woman has to deliver an outstanding performance to prove her and consequently this situation leads woman to another effort beyond the career line. Male staff and organizations by remaining insensitive to female staff's difficulties and women having to undertake most of the responsibilities by themselves constitute another obstacle for female staff.

As a result of the research, female staff intensively perceives the glass ceiling concept and the reason that male staff give less response to the asked questions than female staff is because this situation is not an issue for them. The reason why male staff shows low awareness to female staff issues is that they take the powerful side and are not interested in female staff's power related issues. One of the reasons that male staff gave responses indicating that they are on power side might be because they consider the power as a qualification representing them with the impact of culture they lived in while they were raising and therefore they take the authority naturally. It might be a research subject in the prospective studies whether the male staff with children perceives the glass ceiling concept more. Another research subject would be to overlook the questions from perspective of ruler 
and ruled. It might be possible to have knowledge if individuals look from different perspectives of the ruler and ruled positions and to know if they perceive glass ceiling and power distance differently even if female staff starts thinking as men when they reach the top executive levels in the analysis results which were executed by ruler and ruled separation.

It was found unnecessary to make the factor analysis from the procedural aspect in this study; because every question's relation to the other question was taken into the consideration in the analysis of this study. In this case there was no need to classify and compare the questions as in the factor analysis. The findings can be verified using the factor analysis method in the prospective studies. Since the study was executed only in one culture, further research is needed in other culture to compare the results. The prospective studies should be kind of studies that reveal how this relation is in countries with high and low power distances. This research is limited with the survey applied individual's answers, individuals' sincerity, and perception level and the generalizability of the research is limited with attendees who were involved in the paradigm.

\section{References}

Akçamete, C. (2004). Kadın ve erkek yöneticilerin kadınların ust düzey yönetici olmalarına yönelik tutumlarının ve cam tavan sorununun incelenmesi:Bankalarda bir uygulama (Unpublished master's thesis). Hacettepe University, Institute of Social Sciences, Ankara, Turkey.

Aktaş, A., Algör, S., \& Cengiz, F. (2009). Turizm sektöründeki kadın yöneticilerin cam tavan sendromu açısından değerlendirilmesi:Antalya'da bulunan konaklama işletmelerinde yapılan bir araştırma. Paper presentd at the Seventeenth National Conference on Management and Organization, Eskişehir, Turkey.

Arbak, Y., Kabasakal, H., Katrinli, A. E., Özmen Timurcanday, Ö. N., \& Zeytinoğlu, U. I. (1998). Women managers in Turkey: The impact of leadership styles and personality. Journal of Management Systems, 10(1), 53-61.

Aytaç, S. (1997). Çalışma yaşamında kariyer. İstanbul: Epsilon Yayıncılık Publishing.

Baumgartner, M. S., \& Schneider, D. E. (2010). Perceptions of women in management: A thematic analysis of razing the glass ceiling. Journal of Career Development, 37(2), 559-576.

Baxter, J., \& Wright, E. O. (2000). The glass ceiling hypothesis: A comparative study of the United States, Sweden, and Australia. Gender \& Society, 14 (2), 275-294.

Besler, S., \& Oruç, İ. (2010). Women managers in printed media and Turkey. Anadolu Üniversity Journal of Social Sciences, 10(1), 17-38.

Bingöl, D. (2006). Insan kaynakları yönetimi (6 $6^{\text {th }}$ ed.). İstanbul: Arıkan Publishing House.

Boone, J., Veller, T., Nikolaeva, K., Keith, M., \& Houran, J. (2013). Rethinking a glass ceiling in the hospitality industry. Cornell Hospitality Quarterly, 54(3), 230-239.

Caceres-Rodriguez, R. (2011). The glass ceiling revisited: Moving beyond discirimination in the study of gender in public organizations. Administration \& Society, 45(6), 674-709.

Daugherty, E. L. (2012). Executive women in business: Exploring challenges and pathways of specialty areas. International Journal of Business Strategy, 12(1), 47-55.

Doğramac1, E. (1993). Atatürk`ten günümüze sosyal değişmede Türk kadını. Ankara: Atatürk Culture, Language and History High Institution, Atatürk Research Center Publication.

Dreher, G. F. (2003). Breaking the glass ceiling: The effects of sex ratios and work-life programs on female leadership at the top. Human Relations, 56(5), 541-562.

Ergeneli, A., \& Akçamete, C. (2004). Bankacılıkta cam tavan: Kadın ve erkeklerin kadın Calışanlar ve kadınların ust yönetime yükseltilmelerine yönelik tutumları. Journal of Hacettepe University Economics \& Management Sciences Faculty, 2(22), 85-109.

Gunluk- Senesen, G. (2009). Glass ceiling in academic administration in Turkey: 1990s versus 2000s. Tertiary Education \& Management, 15(4), 305-322.

Hofstede, G. (1984). The cultural relativity of the quality of life concept. Academy of Management Review, 9, 389-398. 
Hofstede, G., \& Hofstede, G. J. (2005). Cultures and Organizations Software of the Mind (2 ${ }^{\text {nd }}$ ed.). New York: McGraw Hill.

Jackson, C. J. (2001). Women middle managers' perception of the glass ceiling. Women in Management Review, 16(1), 3041.

Karaca, A. (2007). Kadın yöneticilerde kariyer engelleri: Cam tavan sendromu uzerine uygulamalı bir Araştırma (Unpublished master's thesis).Selçuk University, Institute of Social Sciences, Konya.

Larwood, L., \& Wood, M. (1995). Training women for management: Changing priorities. Journal of Management Development, 14(2), 55-65.

Maznevski, M., Nason, S., \& DiStefano, J. (1993). Fourteen faces of culture: A new instrument for understanding cultural differences. Paper presented at the academy of International Business Annual Meeting, Maui, Hawaii.

Menteş, A. (2010). The importance of quantitative factors at identifying glass ceiling problem: A study on ISE 100 index firms. Istanbul University Journal of Faculty of Political Sciences, 43, 97-108.

Meyerson, D. E., \& Fletcher, J. K. (2006). A modest manifesto for shattering the class ceiling. Harvard Business Review, $78(1), 126-136$.

Örücü, E., Kılıç, R., \& Kılıç, T. (2007). Glass ceiling syndrome and obstacles facing women's advancement to senior management positions: Evidence from balikesir. Celal Bayar University Journal of Economic \& Administrative Sciences Journal, 14 (2), 117-135.

Rosener, J. B. (1990). Ways women lead. Harvard Business Review, 68(6), 119-125.

Sabattini, L., \& Crosby, F. J. (2008). Overcoming resistance: Structures and attitudes. In K. Thomas (Ed.), Diversity resistance in organizations: Manifestations and solutions (pp.273-301). New York: Erlbaum.

Sargut, A. S. (1994). Kültürlerarası farklılaşma ve yönetim. Ankara: Verso Publishing.

Terzi, A. R. (2004). A research on power distance and uncertainty avoidance of university students' perceptions. Afyon Kocatepe University Journal of Social Sciences, 7(2), 65-75.

Tversky, A., \& Kahneman, D. (1991). Loss aversion in riskless choice: A reference dependent model. Quarterly Journal of Economics, 106(4), 1039-1061.

Varoğlu, A. K., Basım, N., \& Erçil, Y. (2000). Bilimsel araştırma yönetimine farklı bir bakış; analitik düşünce ve bütünleşik düşünce modellemeleri ile belirsizlikten kaçınma ve güç mesafesi Araştırması. Paper presented at the Eighth National Management and Organization, Nevşehir.

Wirth, L. (2001). Women in management: Closer to breaking through the glass ceiling? In M. F. Loutfi (Ed.), Women, gender, and work (pp.239-250). Geneva: International Labour Office.

Yoğun Erçen, A. E. (2008). Kadınların cam tavanı aşma stratejileri:Büyük olçekli türk işletmelerinde bir inceleme (Unpublished doctoral dissertation). Çukurova University Institute of Social Sciences, Ankara.

Zeybek, E. (2010). Kariyer engelleri ve cam tavan:Ankara'da faaliyet gösteren 4 ve 5 ylldızl otel işletmelerinde bir uygulama (Unpublished master's thesis). Gazi University Institute of Education Sciences, Ankara. 